\title{
A Lesson Study-based Challenge on Developing Students' Interaction in EFL Class through Workshop Technique
}

\author{
Lutfi Istikharoh \\ English Education Department \\ Universitas Muahammadiyah Purwokerto \\ Purwokerto, Indonesia \\ lutfiistikharoh@ump.ac.id
}

\begin{abstract}
In recent years, the field of Teaching English as a Foreign Language has developed into a dynamic worldwide community of language teaching professionals that seeks to improve the quality of language learning through Lesson Study. This paper presents the implementation of Lesson Study in a TEFL class as an effort of evolving students' interaction during learning processes. Due to the function of English as a foreign language in Indonesia, English becomes both material to learn and a medium of Instruction. Consequently, the students are demanded to not only be able to comprehend it as a learning subject but also as a means of communication. Some problems which deals with how English learning process can accomodate the students to optimize the use of English in class interaction arise. One of them is insufficient opportunity for the students to communicate using English. To cope with the problems, a Lesson Study (LS) with six cycles during a half term of sixth semester was implemented. The focus of the action was on making the students able to build a good interaction with their classmates. Both model lecturer and observers designed the learning process through collaborative-based workshops in which the students were accomodated in holding tight interaction in English. A good result shows that almost in all open lessons, the students were active and participative during both group and class discussion. Workshop techniques facilitated the students to not only discuss and simulate the materials with their own group members but also with other classmates.
\end{abstract}

Keywords: collaborative learning, open lessons, student-centered learning

\section{Introduction}

In learning languages, a distinction is usually made between mother tongues, second languages, and foreign languages. A mother tongue is the first language or languages one learns (or acquires) as a child. When immigrants come to a new country and learn the language of that country, they are learning a second language. On the other hand, when English-speaking students in the United States learn French or Spanish in school, or when Brazilians study English in Brazil, they are learning a foreign language. The acronyms ESL and EFL stand for the learning of English as a Second and as a Foreign Language.

In its status whether as a second or a foreign language, it is a language that widely used in society and learners need to acquire English in order to survive in society. There are some issues that seem to be important at any particular point in time and the approaches to teaching that are followed in different parts of the world reflect contextual factors such as current understanding of the nature of second and/or foreign language learning, educational trends and practices in different parts of the world, and the priorities the profession accords to specific issues and practices. In the last 30 years or so, the field of
Teaching English as a Second or Foreign Language has developed into a dynamic worldwide community of language teaching professionals that seeks to improve the quality of language teaching and learning through addressing the key issues that shape the design and delivery of language teaching (Richards and Renandya, 2002: 2).

In recent years lecturers of English as a Foreign Language (EFL), or English as a Second Language (ESL), have been paying increasing attention to identifying the needs of their students, to students' attitudes towards English and their reasons for learning it. This attention to learners' needs can be seen in countries such as Indonesia where English is regarded as a foreign language and is largely treated as an academic subject in the school system and is not widely used outside of the classroom. The same attention to learners' needs can also be seen in countries such as Malawi and Sri Lanka where English is taught as a second language, where English is widely used and is perceived as essential to success.

English is the only one foreign language which is enlosed in the Curriculum which runs in Indonesia. The language is introduced and taught in all levels of education as both extracurricular and main 
subject of learning. However, laerning English in University level, especially in English Education Department (hereafter is EED) is quite different from that in the other levels of education. Leaning English in English Education Department, University of Muhammadiyah Purwokerto is not only learning how to be good at using and mastering it but also how to teach it as both material and medium of instruction.

Considering the use of English as material and media of instruction, learning English becomes much more challenging for both the lecturers and the students. The lecturer should be very creative in designing the learning process, while the students must be active in joining the process of gaining the knowledge (Kimble dan Garmezy, 1963: 133 cited in Brown, 2001: 7). Conversely, the fact shows that the learning process in EED was still far from being perfect, especially in facilitating the students to be active in class discussion. This is what Teaching English as a Foreign Language (hereafter is TEFL) should be a field of study to make the students able to be good teachers. TEFL is taught in both semester V and VI. The lecture covers three branches of teaching methodology: approach, method and technique. Most of the students mastered the material very well, they compehended and were able to explain what approach, method and technique, and their variety, however, their limited interaction made them difficult to work collaboratively. The students still found difficulies to build a good and interactive communication with the class members through Focused-group Discussion.

Most students stated that it is difficult to maintain active interaction with the others since not all students have a good willing to get involvd in the group discussion. A big number of students tended to be followers without having sufficient confidence and comprehension to be active in their collaborative group work..

Considering these big problems for the lecturer candidates in EED, a solution is needed. Having discussed this with the collegues and the chief of EED, a lesson study was designed. It was aimed at making the students of TEFL class able to not only comprehend the materials and implement it in the real teaching and learning process through workshop technique but also make them able to maintain a good class interaction through collaborative-based workshops. This collaborative-based workshops were aimed at facilitating the students to have good interaction and to make them get involved in collaborative group work.

\section{Teaching English as a Foreign Language (TEFL)}

In countries where English is taught as a foreign language, as opposed to a second language, providing meaningful lessons and stimulating motivation in this context is a challenge. However, it is important that the lecturers should help the students understand the necessity of learning English. Those of the students who will be going on to university or college will find that many of the textbooks and articles they will be asked to read will be in English. If possible, the lecturers could try to provide interesting and interactive teaching-learning process (TLP) through designing a good teaching methodology. Their testimony should go a long way toward convincing the students that learning English could be very beneficial.

Methodology in language teaching has been characterized in a variety of ways. A more or less classical formulation suggests that methodology is that which links theory and practice. Theory statements would include theories of what language is and how language is learned or, more specifically, theories of foreign language acquisition (FLA). Such theories are linked to various design features of language instruction. These design features might include stated objectives, syllabus specifications, types of activities, roles of lecturers, learners, materials, and so forth (Rodgers, T.S., 2001: 1). Design features in turn are linked to actual teaching and learning practices as observed in the environments where language teaching and learning take place. This whole complex of elements defines language teaching methodology.

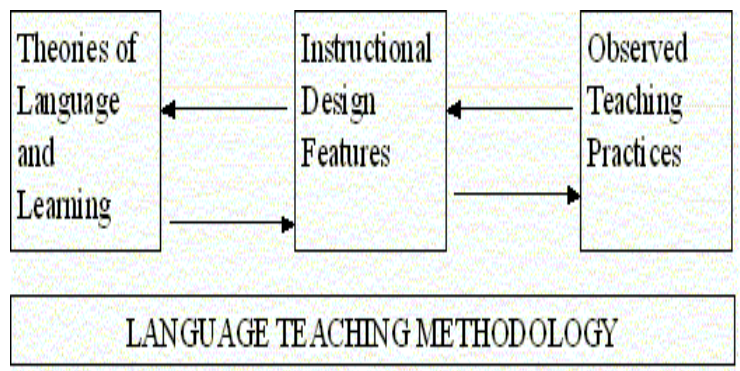

Figure 1. Language Teaching Methodology

Methodology of Teaching English is concerned with the question of how to learn and teach English - English language and linguistics, English literature(s) and culture(s) (Brown, 2001). It addresses everybody who aims at the teaching profession in foreign language education at schools or in the field of continuous education. The skills to teach or train and to impart information and knowledge to others is vital for a wide range of jobs outside the traditional field of teaching, for instance the information industry in general, or trainee programmes and personnel management in particular.- Existential for every student is also the ability to study and learn, fast and efficient. The Methodology of Teaching English deals with the two mirror-like aspects: teaching and learning how to learn. It therefore conveys the basic skills for all students of English; it helps the students to become 
aware of learning strategies, to aquire study techniques such as skimming and skipping for instance or representation skills.

Methodology of Teaching English can also mean fun, because creativity and "real-life" application are the basis and focus (Chemnits, 2008: 1). Traditional resources have to be combined with new multi-media and computer-based techniques to create an interactive cross-cultural learning environment. Here, the traditional role play may lead the way into intercultural meetings and chats over the internet, familiarizing the students with new techniques to learn and teach discourse and cultural aspects, for instance. Presentations as brochures, CDs, or WEB-pages might be part of a new methodology to reach teaching and learning objectives such as the four basic skills, reading, listening, writing, speaking and at the same time convey linguistic, literary, and/or cultural information (Nunan, 2003). Methodology of Teaching English provides students with the didacticpedagogical and psycholinguistic knowledge to develop concepts for innovative teaching up to the latest and prospective challenge of teleteaching.

Methodology of Teaching English is linking theoretical, scientific studies with applied, practiceoriented research and may function as bridge to internships and future jobs (Harmer, 2001). It offers a wide range of opportunities for project work and empirical research.

Within methodology a distinction is often made between methods and approaches, in which methods are held to be fixed teaching systems with prescribed techniques and practices, whereas approaches represent language teaching philosophies that can be interpreted and applied in a variety of different ways in the classroom. This distinction is probably most usefully seen as defining a continuum of entities ranging from highly prescribed methods to loosely described approaches.

\section{Workshop Technique}

Various teaching techniques have already been used by lecturers all around the worlds from thousand years ago. The aim of this is making both the learning process run well and the students learn the material optimally. However, not all teaching techniques are appropriate to all students. Some considerations are needed to balance the appropriateness between the teaching techniques and the materials, the students' needs and characters, the curriculum and then the media which can support the learning process.

To overcome those obstacles, especially in TEFL class in EED is that workshop technique is considered the most appropriate one with the materials and students' need for their profession as a lecturer.
Workshop is a technique in which people are gather and disscuss a particular problem and its solution (Romivera, 2013). There are assisted by an expert of the field they belong to. Moreover, workshop technique "allows students to produce when they are 'ready'. Improvement comes from supplying communicative input, not from forcing production" (Krashen in TJ Taylor, 2007). The activities covered in workshop technique are collaborative group discussion, presentation, class discussion and simple simulation or demonstration.

In TEFL class, the workshop technique is designed to make the students able to discuss a particular material in small group activity, present it in the class, discuss it together with the whole members of the class and simulate or demonstrate it. Commonly, the presenters will be the lecturer(s) and the audiences will be the students. They have to collaborate well since the learning achievement of the material demonstration will be based on the participation of both presenters and audiences. This participations will lead them to the success of learning, covering affective, cognitive and skill domains.

\section{Lesson Study}

A teaching action which can be initiated to develop the quality of education, especially in the learning process is namely Lesson Study. Lesson Study (hereafter is LS) is introduced in Japan since more than 30 years ago (Sato, 2015).

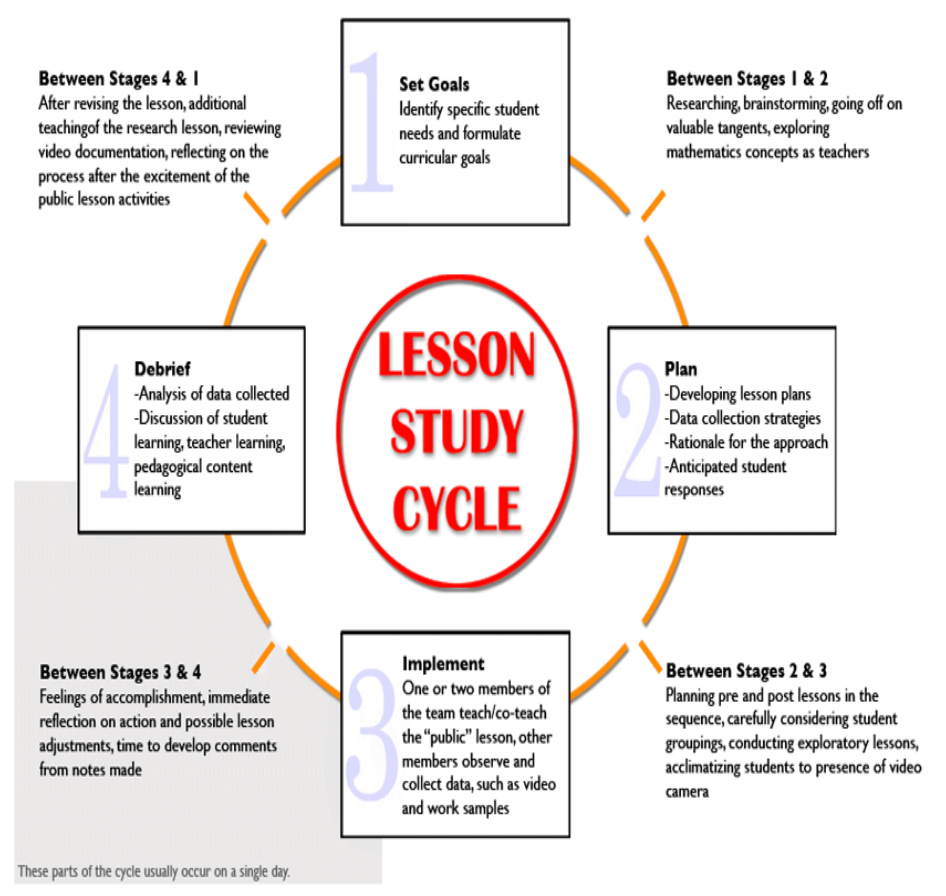

Figure 2. The Cycle of Lesson Study 
The Implementtaion of Lesson Study presented in Figure 2 covers four stages, they are Goal Setting, Planning (PLAN), Implementation (DO) and Debriefing/ reflection (SEE).

The focus of this action is making the students able to boost their learning quality through collaborative work. Through this teaching action, the students are facilitated to be able to work in pairs or group and able to develop their both comprehension and communication ability with the class members.

Before implementing workshop technique in LS, the team of LS developed and arranged a design of learning activities for each meeting. During the implementation of LS in six meetings, the focus of observation was on the students interaction in doing collaborative group working.

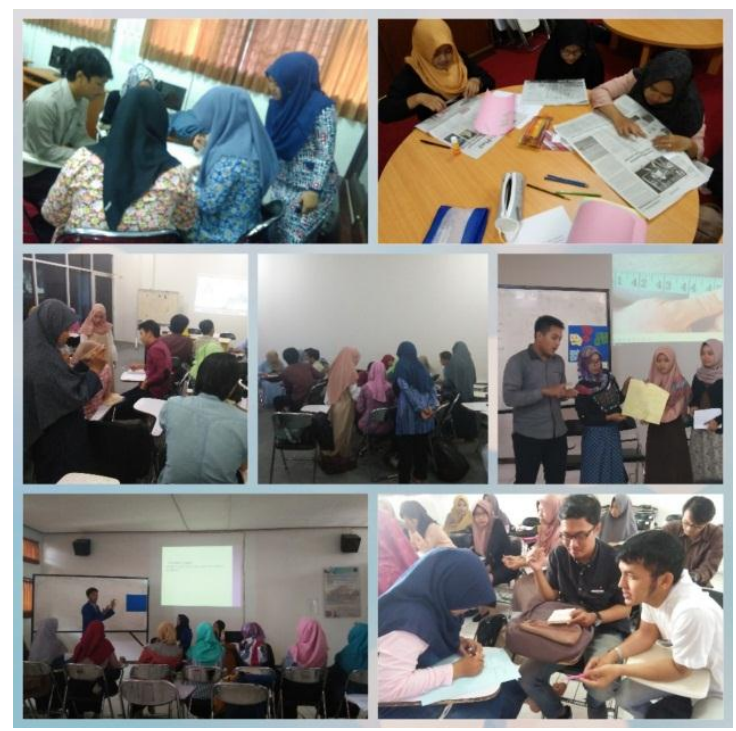

Figure 3. LS Implementation_DO

The open lesson in LS is shown in Figure 3. Some observers focused on the students' activities. All things happened during the learning processes were noted as a point to discuss in Reflection Stage.

The final step of a cycle of LS is that all team members discussed the condition happened during the observation focusing on the students' interaction. All activities which cannot accomodate the students' collaboration and interaction were redesigned.

Lesson Study is an alternative to see our teaching in the teaching of others (Gebhard, 2000: 31). When lecturers observe others to gain knowledge of self, they have the change to construct and reconstruct our knowledge. While observing other lecturers, it is possible to collect samples of teaching in a variety ways. They can take fast notes, draw sketches, tally behaviors and jot down short trascript-like samples of interaction.
Benefits can be revealed through the implementation of LS for the lecturer model, observers and mostly for the students. First, LS can initiate and facilitate the lecturer models to develop their creativity in teaching. They can explore how to be good at not only teaching the students but also motivate and facilitate the students to master and comprehend the materials, well. In addition, lecturer models will be helped in designing the lesson, selecting appropriate madia, classifying graded materials and class activities, mostly in observing the students activity during the learning process.

Second, to the lecturers who observe the model lecturer, they will have many experiences and knowledge how to teach with different ways and styles. LS will also build up the lecturers' collaboration, communication and cooperation in promoting qualified learning processes at their school. Moreover, they will find how collaborative work in LS will make them able to select appropriate teaching strategies.

Moreover, the students in an LS program will find at least four beneficial points. The one to start is that the students will be facilitated to comprehend the material through collaborative learning. Then, they will be able to explore and share their knowledge with their friends in free ways. In addition, the students are accomodated to communicate with the class members. The last but not least, LS will develop their ability to be autonomous learners which consequently will make them able to appreciate the other friends' existance. On a whole, the students wil find a good way to build and maintain their social and collaborative interactions with the class members.

\section{Students' Interaction}

Some positive things happened during the TEFL learning process through workshop technique in Lesson Study program. Six cycles were implemented during a semester in the five semester students in academic year 2014/2015. At first, the students were only trying to read some books, compile the materials and present it in the learning process. They worked individually and ignored the importance of the other friends in the process of developing their understanding of the material. During the presentation, the students only discussed the materials without practicing how to use it in the real learning process. The consequence of this is that the students cannot develop their togetherness through tight interaction.

Through workshop, the students were not only able to comprehend the materials and implement them in the real learning process through simple demonstration but they also will have sufficient time to build a good interaction when they have to design their workshop well. 
In the implementation of Lesson Study in TEFL class, the observation which was done by two other lecturers helped the lecturer model designing better learning processes which focused on the students. The whole results were satisfactory.

First, the students were enthusiatic in learning the material, especially when the other lecturers observed their learning processes. At the beginning, some students wanted to show their activeness and participation during the discussion session, but it was becoming better when finally they were really willing to show the lecturers that they are good at discussing the materials. For those, as lecturers stepping into a new educational system, it is important to inform themselves of their students' needs and attitudes towards learning English so that from the beginning they can play an effective role in their classroom. Conducting a need assessment, even an informal one, is therefore an important first step in their jobs (Bowman S.; Burkart, G.; Robson, B., 1989: 6).

Second, most students were trying to be ready all the time to share, comment and rebutt the materials with their friends as a positive result being observed by their lecturers. They did not want to make any mistakes when they pose their idea and questions during the class discussion. Consequently, they have to be able to comprehend the material first before they join the lesson. This also indicates that the students' interaction during debriefing activity was getting better.

Another point revealed is that the students' collaboration improved and their communication was becoming better. None of them were neglected by both the lecturer and their friends. All of them were get involved during the class discussion, demonstration and reflection. In addition, through workshop technique, the students learnt through hands on experience. This achievement corellated positively to the students' ability in teaching in both Micro Teaching clhttps://www.ump.ac.idass and Teaching Practice at schools.

On a whole, both workshop and LS facilitated the students to be able to learn through vast ways. They could improve their collaboration and communication with other friends. They also were able to comprehend the material through applicative way, elaborating their critical thinking through collaborative work and lecturer's assistance.

\section{Conclusion}

Lesson Study is approved as a good way of improving the quality of students' learning. The implementation of LS in TEFL Class was designed by implementing workshop as a technique of learning. Through workshop in LS, there are at least four results revealed: 1). The students were more enthusiastic in joining the lesson where they did not only present the materials and demonstrated it as well but also contribute to the class discussion; 2). The students were more active and well-prepared when they got involved in the discussion as a result for being observed by some lecturers; 3). The students' communication were much better than before, and 4). The students were good at working collaboratively with others.

A lesson learnt from this teaching action is that LS is a good way to optimize the quality of learning process. This action will be becoming better when lecturers are able to provide some challenging learning activities which can accomodate the students to actively participate in collaborative work.

\section{References}

[1] Bowman, B; Burkart,G.; Robson,B. 1989. Teaching English as a Foreign and Second Language. Washington: Peace Corps.

[2] Brown, H. Douglas. (2001). Teaching by Principles: An Interactive Approach to Language Pedagogy. San Francisco: Longman, Inc.

[3] Chemnitz. 2008. TESOL-Teaching English to Spekers of Other Languages. Available online at http://www.tu-chemintz.de.com

[4] Gebhard, Jerry G. (2000). Teaching English as a Foreign or Secon Language. USA: University of Michigan Press

[5] Harmer, Jeremy. (2001). The Practice Engliah Language Teaching. Essex: Pearson Education Limited

[6] Manaabu, Sato. 2015. Lesson Study for Learning Community (Lecture Material). Tokyo: JICA

[7] Nunan, David. 2003. Practical English Language Teaching. New York: McGraw-Hill.

[8] Richards, J.R. and Renandya, W.A. 2002. Methodology in Language Teacahing. New York: Cabridge University Press.

[9] Rodgers, T.S. 2001. Language Teaching Methodology. Available online at http://www.cal.org. Acesses on 1 March 2008.

[10] Romivera. (2013). Lokakarya (Workshop). Available online at https://romivera.wordpress.com/2013/06/03/lokak arya-workshop/. Accessed on 15 Oktober 2014.

[11] TJ Taylor. 2007. Teaching Methods: An Interview. Available online at http:/www.tjtaylor.net/engligh/teaching-methodgrammar-translation.com 